\title{
A new palliative surgical technique for high risk Total anomalous pulmonary venous connection (Sarmast-Takriti shunt)
}

\author{
Hossein Sarmast ${ }^{*}$ (D) and Ahmad Takriti
}

\begin{abstract}
Background: Total Anomalous Pulmonary Venous Connection (TAPVC) is a rare heterogeneous condition That accounting for 1.5-3\% of congenital heart diseases. It is characterized by failure of the Pulmonary Venous Confluence (PVC) to be directly connected to the left atrium in combination with a persistent splanchnic connection to the systemic venous circulation. The most critical status occurs when it is accompanied by pulmonary venous obstruction. Managing of this situation is very difficult and in fact, pulmonary venous obstruction is usually lethal. The real aim of this study is offering a new palliative surgical technique (Sarmast - Takriti Shunt) in order to alleviate the patient's signs and symptoms until becomes ready for the main surgical correction.

Case presentation: The study included a 4-day old, low birth weight boy who suffered from Critical Obstructive Total Anomalous Pulmonary Venous Connection. The decision was made to perform the new palliative technique using Gore - Tex (ePTFE). Anastomosis was established without Cardiopulmonary Bypass (CPB) between Pulmonary Venous Confluence (PVC) and the left atrial appendage. Therefore the Sarmast - Takriti Shunt (STS) was taken place.

Conclusion: After completion of the procedure, the pressure gradient across the venous confluence and the Left innominate vein became zero. Cyanosis, agitation and feeding Problem subsided. Three days later, when he was discharged, arterial oxygen saturation had reached as high as 91\%. After 7 months we perfomed the main correction.

Keywords: Total anomalous pulmonary venous connection - Sarmast, Takriti shunt (STS), Pulmonary venous obstruction, Low birth weight- pulmonary venous confluence -palliative surgical technique- congenital heart diseasecardiopulmonary bypass
\end{abstract}

\section{Background}

Total anomalous pulmonary venous connection is a rare heterogeneous anomaly,accounts for $1.5-3 \%$ of congenital heart diseases [1]. It is characterized by abnormalreturn of whole Pulmonary venous blood flow to the right atrium or systemic venous tributaries due to its persistent splanchnic connection [2]. A concomitant right to left shunt, commonly via an interatrial communication, is required for survival after birth. Darling classified it in four categories: Supra-cardiac 45\%, cardiac 25\%, Infracardiac $25 \%$ and mixed type 5-10\% [3]. At one end of the spectrum, there are completely unobstructed circulation, these neonates present with a large left to right

\footnotetext{
* Correspondence: abcmoghim@gmail.com

Department of Cardiac Surgery Hospital, Damascus university, Mouasat

Square Omar ben Abdulaziz Street, Damascus, Syria
}

shunt manifestations. At the other end there are severe PVO neonates born with TAPVC have poor prognosis with approximately $80 \%$ mortality in the first year of life. Both obstructed and non-obstructed types of TAPVC pose an absolute indication for surgical repair [4]. In PVO type without intervention the median survival is 2 months, with the shortest survival being 1 day. Despite greatly improved neonatal care and surgical techniques over the last decade, TAPVC operation is still associated with high hospital mortality, up to $20 \%[5,6]$.

\section{Case presentation}

A 4 -day old, low birth weight boy ( $\mathrm{w}=1950 \mathrm{~g})$ was presented to our departmentwith discrete but increasing cyanosis, tachypnea, respiratory distress, hepatomegaly, hypoxia $(\mathrm{Sao} 2=70 \%$ ), gasping, poor feeding and severe metabolic acidosis. The prenatal course was uneventful

(c) The Author(s). 2019 Open Access This article is distributed under the terms of the Creative Commons Attribution 4.0 International License (http://creativecommons.org/licenses/by/4.0/), which permits unrestricted use, distribution, and 
and he was born by normal vaginal delivery on gestational age $=38.5 \mathrm{w}$. The patient didn't carry any congenital heart disease (CHD) history in his genetically close relatives (first, second and third degree). Immediate and brief work up was carriedout. Chest X Ray (CXR) showed normal heart size with ground glass appearance in all the lung fields (Fig. 1a). Color doppler and 2 Dechocardiography revealed the total anomalous pulmonary venous connection (TAPVC - supra cardiac type), accompanied by significant gradient between the drainage point of vertical vein to the left brachiocephalic vein and the pulmonary veins with flow acceleration $>3.0 \mathrm{~m} /$ sec (pulmonary venous obstruction). It was also uncovered presence of the ASD secundum, as the natural last resort for being alive. The vertical vein was noted to be compressed as it coursed posterior the left pulmonary artery and anterior the left main bronchus (Fig. 1b). According to the aforementioned findings, the boy had almost met most of incremental risk factors leading to mortality after conventional operations. Therefore the decision was made to a new palliative surgical procedure for the first time. The patient suffered from critical pulmonary venous obstruction (PVO) with severe hypoxia, metabolic acidosis and Pulmonary hypertension (PHT) besides the restricred time for preoperative evaluation and preparation, therefore in order to preoperative medical stabilizing we conventionally used $100 \% \mathrm{O} 2$ with the aim of promoting respiratory alkalosis as well as nitric oxide as a pulmonary vascular dilator as a last resort. Under general anesthesia, median sternotomy and partial thymectomy were carried out. The pericardium was opened in vertical fashion then prudent purse-string sutures as stand by were placed on ascending aorta and right atrial appendage (without using $\mathrm{CPB}$ ). After intravenous heparinization $(100 \mathrm{U} / \mathrm{kg})$, at first some dissections were done from left lateral side between heart and pulmonary venous confluencethen the dome of the left atrium was exposed. The posterior pericardium just superior the dome of LA was incised and PVC was appeared (Fig. 2). Using a side - biting clamp on the PVC, a longitudinal incision was made. The proximal head of a Gore -Tex (ePTFE) with appropriate size (diameter $=6$ $\mathrm{mm}$ ) that had been prepared and beveled, was anastomosed to PVC using continuous 6-0 polypropylene suture. Under topical cooling of heart with aim of more and better protection of heart in case we didn't use CPB as well as for control of cardiac movements, and using a side-biting clamp on left atrial appendage(LAA), the distal end of Gore-Tex was anastomosed to LAA. After deairing with heparinized saline as routine, the clamp was removed. The Sarmast -Takriti Shunt (STS) between PVC and LA was established (Fig. 3). Immediately after completion of the procedure, cyanosis began to decrease. In order to the prophylactic anticoagulant therapy, we initially administered low dose rectal ASA $(5 \mathrm{mg} / \mathrm{kg} / \mathrm{d})$ followed by oral route $(10 \mathrm{mg} / \mathrm{kg} / \mathrm{d})$ from the $\mathrm{POD}=1$. We performed the main operation 7-months later with excellent outcome when he had already sustained satisfactory weight $(\mathrm{w}=7030 \mathrm{~g})$, as follows: After the establishment of $\mathrm{CPB}$, the shunt was removed. To reduce the the risk of residual obstruction of PVC due to pocket-like contraction our team preferred modified septosuperior approach (komarakshi technique). A direct anastomosis between PVC and L. A, ligation of the $\mathrm{VV}$ and closure of ASD with autopericardial patch were achieved in one stage repair.

\section{Discussion and conclusions}

Evaluation of pressures before intervention in the operation room and after correction are illustrated in the (Table 1.). Immediately after completion of surgery (STS), the pressure of PVC decreased to the point where its pressure gradient became zero. Blood oxygenation improved up to $84 \%$ (preoperative Sao 2 was $70 \%$ on

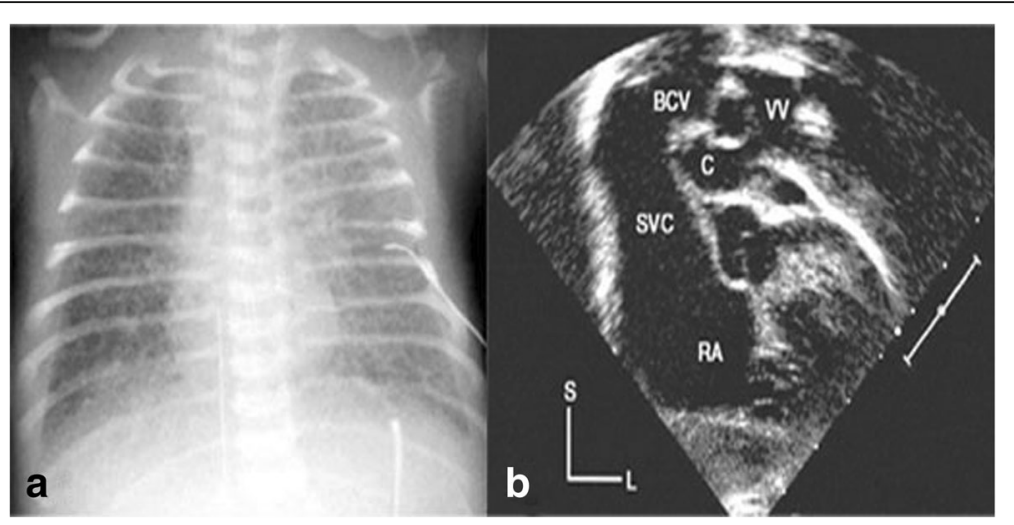

Fig. 1 4-days old male with total anomalous pulmonary venous connection accompanied by pulmonary venous obstruction: a- CXR: Note mild cardiac enlargement and evidence of pulmonary venous hypertension ("ground glass" appearance). b- 2D-Echocardiography shows compressed vertical vein between It.pulmonary artery and It.main.bronchus 


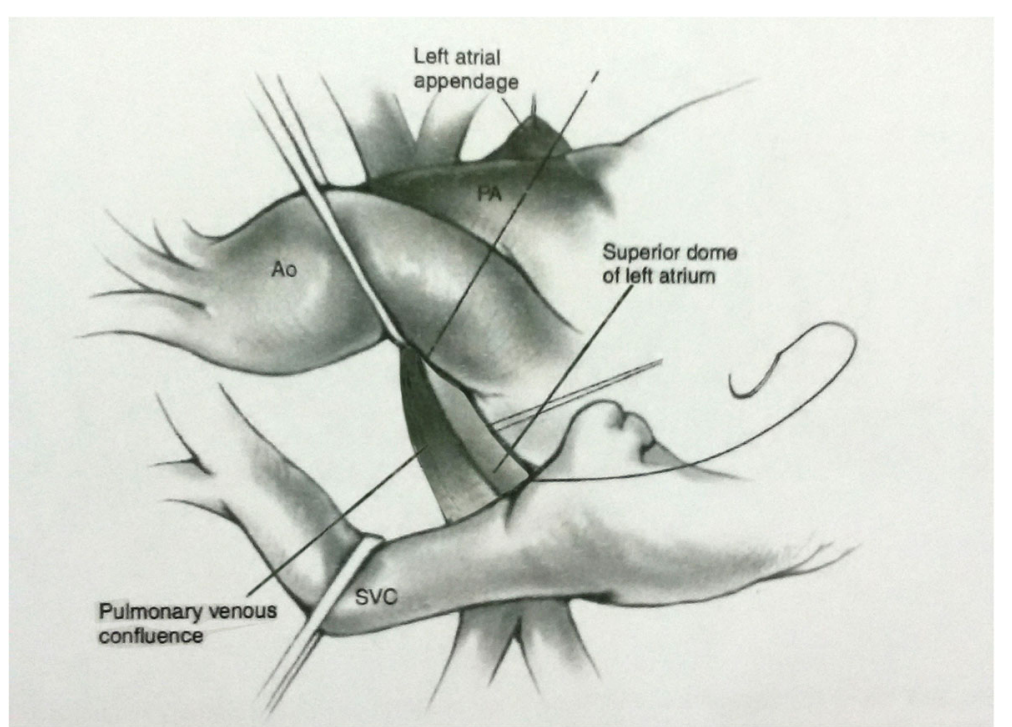

Fig. 2 Schematic illustration of superior approach in 4-days old male with total anomalous pulmonary venous connection

$100 \%$ oxygen) and cyanosis, agitation, feeding problem subsided. Three days later, when he was discharged, arterial oxygen saturation had reached as high as $91 \%$. Despite good advances in treating of TAPVC in recent decades, this severe malformation in its various anatomical forms remains a challengeable entity during early infancy. Significant obstruction to pulmonary venous drainage results in pulmonary edema in the presence of a normal size and shape of the heart and cardiogenic shock which is rapidly lethal if untreated. Our patient preoperatively suffered from significant gradient between the drainage point of vertical vein to the left brachiocephalic vein and the pulmonary veins with flow acceleration $>3.0 \mathrm{~m} / \mathrm{sec}$ (pulmonary venous obstruction) but in postoperative echocardiography, midflow acceleration $0.8 \mathrm{~m} / \mathrm{sec}$ was found at the conduit site. This flow and patency was maintained up to the second operation, showing an identical median Vmax of $0.8 \mathrm{~m} / \mathrm{sec}$. Neither turbulent nor continious flow was observed in the conduit. Almost all reports have declared that perioperative high mortality associates with $\mathrm{PVO}$, low weight (W<2.5-3 kg), early age $(\mathrm{A}<2 \mathrm{~m})$, severe preoperative acidosis, long time of aortic Cross Clamp (ACC) and cardiac arrest. The second frontier in the treatment of TAPVC is represented by postoperative PVO. In such a difficult situations, if patients survive from operation, most of them will require multiple postoperative surgical interventions due to recurrent PVO with an increasingly poor outcome at each representation [7]. Medical efforts are minimally effective in managing the ensuing hemodynamic and metabolic problems so their use is limited to provide some short lived conservative therapy until definitive surgical treatment is carried out. PVO is usually lethal, even with reoperation and extensive

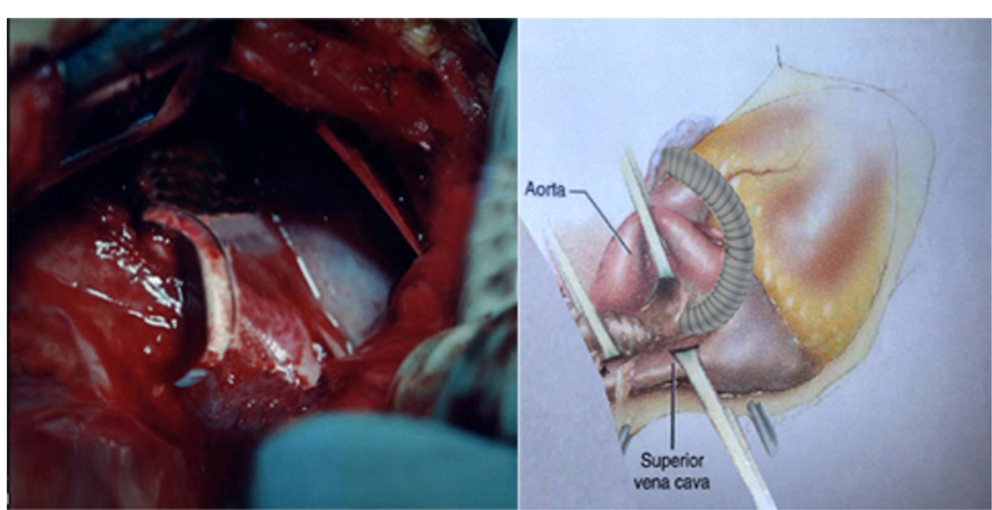

Fig. 3 Schematic and operational photo illustrations of sarmast - takriti shunt (STS) in 4-days old male with total anomalous pulmonary venous connection 
Table 1 Preoperation and postoperative cardiac pressures of 4-days old male with total anomalous pulmonary venous connection accompanied by pulmonary venous obstruction

\begin{tabular}{lllllll}
\hline & PVC mean pressure & Left brachiocephalic vein & Left atrium & Right atrium & Right ventricle & Pulmonary artery \\
\hline Preoperative pressures $(\mathrm{mmHg})$ & 29 & 9 & 8 & 9 & $61 / 13$ & $59 / 31$ \\
Postoperative pressures $(\mathrm{mmHg})$ & 8 & 8 & 9 & 8 & $32 / 10$ & $28 / 15$ \\
\hline
\end{tabular}

attempts at revision or repair [8]. This lack of success has led to alternative treatments such as balloon dilatation and stenting. The Rashkind Operation or Balloon Atrial Septostomy (BAS) has been used with some success to decompress the pulmonary venous pressure and improve $\mathrm{C} / \mathrm{O}$ in the restricted ASD, but these don't appear to provide additional benefit. Moreover several reportshave proposed the use of percutaneous angioplasty and stenting of the obstructed vein to palliate shock and improve preoperative metabolic state. Research showed during the median cross - sectional follow up of 3.1 years, estimated mortality was $38+/-8 \%$ at 1 year and $50+/-8 \%$ at 5 -years after stent implantation. Necessity for reintervention (owing to occlusion of stent), was $58+/-7 \%$ at 1 -year. In 1996 sutureless repair technique was described, using in situ autologous pericardium for recurrent pulmonary vein stenosis following main TAPVC surgery [9]. Subsequent reports emphasize the utility of this technique in selected patients as main procedure. Despite interest in the sutureless technique, there is little firm evidence that it provides a benefit over conventional techniques used a retrospective analysis to compare the outcomes of death and restenosis after conventional and sutureless techniques. By multivariable analysis, there was no statistically significant difference between the conventional and sutureless techniques. We encountered with a patient, who had almost encompassed all critical risk factors that were sufficient to make the operative prognosis very poor. Routine conventional operative procedures have reported mortality rate up to $\% 50$ and post operative pulmonary venous obstruction (PVO) morbidity rate up to $\% 54$ especially in the obstructive type of TOPVC as well as almost all of them need to the secondoperation. Our patient took more opportunity to gain appropriate weight also heart chambers and pulmonary veins grew adequately. The Sarmast - Takriti Shunt (STS) stablished adequate postoperative hemodynamics for symptomatic neonate and prompt left cardiac side rehabilitation. The STS with confined heparin $(100 \mathrm{U} / \mathrm{kg})$, was carried out without using $\mathrm{CPB}$ with an intention to reduce the morbidity associated with extra corporeal circulation. Eliminating $\mathrm{CPB}$ reduced the cost of the procedure substantially and saved the patient from its inherent complications [10]. .After procedure the enough time was prepared on behalf of the heart to compensate its chambers especially the right ventricle and left atrium and ensure endurable state for the main surgery. Although our experience was limited to STS in supracardiac type, we are optimistic and hopeful to its feasibility and usefulness in other types of TAPVC. Now, we are so satisfied owing to be able to help such a complicated neonate.

\section{Abbreviations \\ ACC: Aortic cross Clamp; ASD: Atrial septal Defect; BAS: Balloon atrial Septostomy; C/O: Cardiac output; CHD: Congenital heart Disease; CPB: Cardiopulmonary Bypass; LA: Left atrium; PHT: Pulmonary Hypertension; POD: Post operative Day; PVC: Pulmonary Venous Confluence; PVO: Pulmonary Venous Confluence; STS: Sarmast_Takriti Shunt; TAPVC: Total anomalous Pulmonary Venous Connection; W: Vertical vein}

\section{Acknowledgements}

The author wish to thank Professor Zahra Sepehrmanesh,Dr. Soroush Sarmast \& Dr. Behina Sarmast for their assistance in this study. Also Dr. Kevin Brady \& Dr. Fariba Brady from the USA state of New Jersey; for their editorial assistance.

\section{Authors' contributions}

All authors have contributed to the conception \& writing the manuscript as well as have approved to the submission of the manuscript.

\section{Funding}

As we are from lower income country, the processing charge has been waived.

\section{Availability of data and materials}

The datasets during the current study available from the corresponding author on reasonable request and for this purpose, the authors received written consent from patient's parents.

\section{Ethics approval and consent to participate}

In 2019,the ethics committee was held in the cardiac surgery center hospital of Damascus university and Department review board approval to publish a case report study entitled " A New Palliative Surgical Technique for High Risk Total Anomalous Pulmonary Venous Connection ( Sarmast-Takriti Shunt) " was obtained. As well as written consent was received from patient's parents.

\section{Consent for publication}

Written consent for publication was obtained from patient's parents.

\section{Competing interests}

The authors declare that they have no competing interests.

Received: 25 April 2019 Accepted: 24 June 2019

Published online: 01 July 2019

References

1. St Louis JD, Harvey BA, Menk JS, Raghuveer G, O'Brien JE Jr, Bryant R 3rd, Kochilas L. Repair of "simple" total anomalous pulmonary venous connection: a review from the pediatric cardiac care consortium. Ann Thorac Surg. 2012;94:133-7. https://doi.org/10.1016/j.athoracsur.2012.03.006.

2. Kouchoukos NT, Blackstone EH, Hanley FL, Kirklin JK. Kirklin/BarratBoyes cardiac surgery. 4th ed. Philadelphia: Elsevier Saunders; 2013. p. 1182-207.

3. Darling RC, Rothney WB, Craig JM. Total pulmonary venous drainage into the right side of the heart; report of 17 autopsied cases not associated with other major cardiovascular anomalies. Lab Investig. 1957:6:44-64.

4. Shi G, Zhu Z, Chen J, Ou Y, Hong H, Nie Z, et al. Total anomalous pulmonary venous connection: the current management strategies in a pediatric cohort of 768 patients. Circulation. 2017;135:48-58. 
5. Duff JP, Joffe AR, Vatanpour S, Moddemann DM, Robertson CM, Alton G, et al. Neurocognitive outcomes at kindergarten entry after surgical repair of total anomalous pulmonary venous connection in early infancy. Pediatr Cardiol. 2015;36:350-7.

6. Cui HJ, Chen XX, Ma L, Xia YS, Yang SC, Zou MH, et al. Surgical treatment of total anomalous pulmonary venous connection under 6 months of age. Chin J Surg. 2016;54(4):276-80.

7. Kato H, Fu YY, Zhu J, Wang L, Aafagi S, Rahkonen O, Slorach C, Traister A, Leung CH, Chiasson D, Mertens L, Benson L, Weisel RD, Hinz B, Maynes JT, Coles JG, Caldarone CA. Pulmonary vein stenosis and the pathophysiology of "upstream" pulmonary veins. J Thorac Cardiovasc Surg. 2014;148:245-53. https://doi.org/10.1016/j.jtcvs.2013.08.046.

8. Masuda M, Okumura M, Doki Y, Endo S, Hirata Y, Kobayashi J, et al. Thoracic and cardiovascular surgery in Japan during 2014: annual report by the Japanese Association for Thoracic Surgery. Gen Thorac Cardiovasc Surg. 2016;64:665-97.

9. Gao XM, Nie ZQ, Ou YQ, He BC, Yuan HY, Qu YJ, et al. Comparison between two surgical techniques to repair total anomalous pulmonary venous connection using propensity score analysis. J Sun Yat-Sen Univ. 2017;38(1):143-50.

10. Sakamoto T. Current status of brain protection during surgery for congenital cardiac defect. Gen Thorac Cardiovasc Surg. 2016;64:72-81.

\section{Publisher's Note}

Springer Nature remains neutral with regard to jurisdictional claims in published maps and institutional affiliations.

Ready to submit your research? Choose BMC and benefit from:

- fast, convenient online submission

- thorough peer review by experienced researchers in your field

- rapid publication on acceptance

- support for research data, including large and complex data types

- gold Open Access which fosters wider collaboration and increased citations

- maximum visibility for your research: over $100 \mathrm{M}$ website views per year

At BMC, research is always in progress.

Learn more biomedcentral.com/submissions 